\title{
PRÓBY TECHNOLOGICZNE WYKONANIA BETONÓW OSLONOWYCH W WYTWÓRNI BETONU TOWAROWEGO
}

\begin{abstract}
W artykule przedstawiono badania technologiczne betonów dla osłon przed promieniowaniem jonizującym. Betony zostały skomponowane z kruszyw magnetytowych, serpentynitowych i barytowych. Celem tej części badań było zapewnienie odpowiedniej urabialności, wytrzymałości na ściskanie oraz ograniczenie skurczu. $\mathrm{W}$ artykule zaprezentowano 8 różnych kompozycje mieszanek. Betony dojrzewały w warunkach normowych do 90 dni i oznaczone zostały wytrzymałość na ściskanie i skurcz. Stwierdzono, że mieszanki B12, B14, B18 są najmniej odpowiednie dla kolejnego etapu badań.
\end{abstract}

Słowa kluczowe: beton ciążki, kruszywo magnetytowe, kruszywo barytowe, kruszywo serpentynitowe, wytrzymałość na ściskanie, skurcz betonu

\section{Wprowadzenie}

Wymagania w stosunku do betonów osłonowych dotyczą różnych właściwości, zależnie od rozmaitych zastosowań betonu w obiektach energetyki jądrowej, składach materiałów i odpadów promieniotwórczych i in.

Podstawowym wymaganiem jest ochrona personelu i otoczenia przed strumieniem neutronów i promieniowaniem gamma. Betony z odpowiednio dobranych kruszyw są głównym materiałem do różnych konstrukcji osłon zewnętrznych w stosunku do powłoki stalowej i ewentualnie ołowianej.

Materiały o wysokiej gęstości zatrzymują promieniowanie gamma, więc ciężkie kruszywa są tu niezbędne. Również hamowanie strumieni neutronów prędkich odbywa się w takich kruszywach. Natomiast materiały zawierające

\footnotetext{
${ }^{1}$ Autor do korespondencji/corresponding author: Brygida Augustyniok, Hydrobudowa-1 BetoniarniaLaboratorium Sp. z o.o., Chlubna 7, 03-054 Warszawa, tel. 662108 171,

b.augystyniok@hydrobudowa1.pl

${ }^{2}$ Grzegorz Nowowiejski, Hydrobudowa-1 Betoniarnia-Laboratorium Sp. z o.o., Chlubna 7, 03-054

Warszawa, tel. 606757 267, g.nowowiejski@hydrobudowa1.pl
} 
wodór są potrzebne do hamowania powolnych i termicznych neutronów. W zwykłym betonie potrzebne jest ok. $0,45 \%$ wodoru, co odpowiada ok. $4 \%$ wody. Ponieważ w całkowicie dojrzałym betonie nie ma dostatecznej ilości wody, to używane są kruszywa zawierającego związki wodoru $(\mathrm{H})$, np. serpentynit [1], [2]. Zawartość chemicznie związanej wody w kruszywie serpentynitowym wynosi $12 \%$ co w przypadku zastosowania kruszyw w ilości $400 \mathrm{~kg}$ odpowiada 48 litrom wody. Zwiększenie ilości wody w mieszance betonowej o około 50 litrów powoduje znaczne zwiększenie wskaźnika wodno-cementowego a co za tym idzie obniżenie wytrzymałości na ściskanie betonu a przede wszystkim jego szczelności. Dodatkowo należy pamiętać, że część dodanej wody nie pozostanie w betonie ulegając odparowaniu.

W elementach betonowych, pełniących funkcje osłonowe oprócz doboru odpowiednich materiałów konieczne jest zapewnienie szczelności oraz jednorodności elementu, stosownie do jego usytuowania. Należy zatem spełnić wymagania technologiczne, co oznacza, że konsystencja betonu powinna umożliwić prawidłowe wykonanie i zagęszczenie mieszanki. Dodatkowo, z uwagi na zwykle masywny charakter osłon, ważnym parametrem betonu osłonowego jest jego skurcz, który zbyt duży może doprowadzić do zarysowania konstrukcji.

Wykonanie osłon $\mathrm{z}$ betonów ciężkich wymaga specjalnej technologii przygotowania mieszanin, ponieważ dobra urabialność jest trudniej osiągalna niż w przypadku zwykłych betonów konstrukcyjnych. Stwarza to konieczność podjęcia prac w celu uzyskania odpowiednich kompozycji betonów osłonowych i szczególnie starannego ich projektowania, uwzględniając oprócz efektów osłony przed różnymi rodzajami promieniowania także wymagania technologiczne oraz zastosowane składniki [1].

Należy również zwrócić uwagę na fakt, że gęstość objętościowa betonów osłonowych jest dużo wyższa od gęstości zwykłych betonów towarowych, co ma znaczny wpływ na mieszanie składników, transport mieszanki betonowej i wreszcie jej układanie w deskowanie i wywierane parcie.

\section{Opis metod doświadczalnych}

\subsection{Materiały i próbki}

Program badań obejmował zaprojektowanie i wykonanie 8 betonów przy zastosowaniu kruszyw magnetytowych z Kiruny w Szwecji, barytowych z niemieckiej kopalni w Wolfach oraz serpentynitowych $\mathrm{z}$ Nasławic. Zastosowano cement hutniczy o niskim cieple hydratacji siarczanoodporny niskoalkaliczny CEM III/A 42,5 N LH/HSR/NA wyprodukowany na potrzeby Projektu „Atomshield" w Oddziale Szkła i Materiałów Budowlanych w Krakowie. Z wymienionych materiałów zaprojektowano składy mieszanek betonowych. Mieszanki zaprojektowano dla wskaźnika wodno-cementowego około 0,48 i ilości cementu około $340 \mathrm{~kg} / \mathrm{m}^{3}$ przy możliwie zbliżonym uziarnieniu. Projektowana klasa wy- 
trzymałości na ściskanie po 28 dniach C30/37. Należy jednak zaznaczyć, że wytrzymałość na ściskanie miała charakter drugorzędny a determinowana była przez ilość cementu i wartość wskaźnika wodno-cementowego potrzebne do uzyskania betonu o niskim skurczu i odpowiedniej szczelności.

Zaroby próbne wykonano w węźle betoniarskim Stetter o pojemności zasypowej $0,75 \mathrm{~m}^{3}$. Po wykonaniu zarobów próbnych za pomocą normowych metod określono konsystencję mieszanki betonowej przy użyciu stożka opadowego, gęstość objętościową mieszanki oraz jej temperaturę. Wykonano próbki sześcienne o boku $150 \mathrm{~mm}$ do badań wytrzymałości na ściskanie betonu oraz próbki o wymiarach 100x100x500 mm do badań skurczu betonu. Próbki były przechowywane w normowo określonych warunkach wysokiej wilgotności i stałej temperatury do chwili badania wg. PN-EN 12390-2:2011. Składniki i właściwości mieszanek betonowych przedstawiono w Tabelach 1, 2.

Przy wykonywaniu mieszanek betonowych założono konsystencję S3/S4 (wg. PN-EN 206), tj. $12-18 \mathrm{~cm}$ opadu stożka. Na podstawie wykonanych wcześniej badań laboratoryjnych przyjęto ilości domieszek mające zapewnić odpowiednią urabialność mieszanek betonowych. W przypadku mieszanek z kruszywem serpentynitowym ilość domieszek potrzebna do uzyskania urabialnej mieszanki była dużo wyższa niż dla mieszanek bez kruszywa serpentynitowego. Zastosowanie dwóch superplastyfikatorów wynikało z trudności w uzyskaniu odpowiedniej konsystencji przy jednoczesnym stałym wskaźniku wodnocementowym.

Tabela 1. Skład i właściwości mieszanek betonowych - Część 1

Table 1. Mix design, fresh mix properties - Part 1

\begin{tabular}{|l|c|c|c|c|}
\hline Skład [kg/m ${ }^{3}$ ] & B11 & B12 & B13 & B14 \\
\hline $\begin{array}{l}\text { Cement CEM III/A 42,5N } \\
\text { LH/HSR/NA }\end{array}$ & 341 & 341 & 342 & 344 \\
\hline Piasek 0-2 mm & 361 & 361 & 362 & 365 \\
\hline Kruszywo serpentynitowe 0-2 mm & - & 266 & - & - \\
\hline Kruszywo serpentynitowe 2-8 mm & - & 885 & 473 & 477 \\
\hline Kruszywo serpentynitowe 8-16 mm & - & 266 & - & 477 \\
\hline Kruszywo magnetytowe 0-5,6 mm & 816 & - & 753 & 879 \\
\hline Kruszywo magnetytowe 0-16mm & 1796 & - & 994 & - \\
\hline Superplastyfikator 1 & 0,99 & 1,92 & 1,45 & - \\
\hline Superplastyfikator 2 & 1,02 & 5,11 & - & 1,46 \\
\hline Woda & 163 & 163 & 164 & 165 \\
\hline \hline Gęstość objętościowa $\left[\mathrm{kg} / \mathrm{m}^{3}\right]$ & 3479 & 2289 & 3089 & 2708 \\
\hline Opad stożka [mm] & 120 & 20 & 20 & 20 \\
\hline Temperatura [ $\left.{ }^{\circ} \mathrm{C}\right]$ & 20 & 15 & 11 & 14 \\
\hline w/c & 0,48 & 0,49 & 0,48 & 0,48 \\
\hline
\end{tabular}


Tabela 2. Skład i właściwości mieszanek betonowych - Część 2

Table 2. Mix design, fresh mix properties - Part 2

\begin{tabular}{|l|c|c|c|c|}
\hline Skład [kg/m ${ }^{3}$ ] & B15 & B16 & B17 & B18 \\
\hline $\begin{array}{l}\text { Cement CEM III/A 42,5N } \\
\text { LH/HSR/NA }\end{array}$ & 337 & 342 & 336 & 345 \\
\hline Piasek 0-2 mm & - & 363 & 356 & 365 \\
\hline Kruszywo serpentynitowe 2-8 mm & - & - & 466 & 776 \\
\hline Kruszywo serpentynitowe 8-16 mm & - & - & - & 179 \\
\hline Kruszywo barytowe 0-16mm & 2828 & 2298 & 1504 & 771 \\
\hline Superplastyfikator 1 & 0,98 & 0,61 & 1,76 & 1,94 \\
\hline Superplastyfikator 2 & - & - & - & 3,1 \\
\hline Woda & 162 & 164 & 161 & 165 \\
\hline \hline Gęstość objętościowa [kg/m $\left.{ }^{3}\right]$ & 3328 & 3168 & 2825 & 2606 \\
\hline Opad stożka [cm] & 190 & 180 & 40 & 100 \\
\hline Temperatura [ $\left.{ }^{\circ} \mathrm{C}\right]$ & 19 & 18 & 18 & 18 \\
\hline w/c & 0,48 & 0,48 & 0,48 & 0,49 \\
\hline
\end{tabular}

Na zdjęciach rys. 1 - 3 przedstawione zostały trzy różne mieszanki charakterystyczne dla programu badań: mieszanka betonowa wykonana przy zastosowaniu kruszywa ciężkiego (magnetyt) - Fot. 1, mieszanka wykonana przy zastosowaniu kruszywa zawierającego związki wodoru (serpentynit) - Fot. 2 oraz mieszanka wykonana przy zastosowaniu zarówno kruszywa ciężkiego (baryt) jak i zawierającego związki wodoru (serpentynit) - Fot. 3.

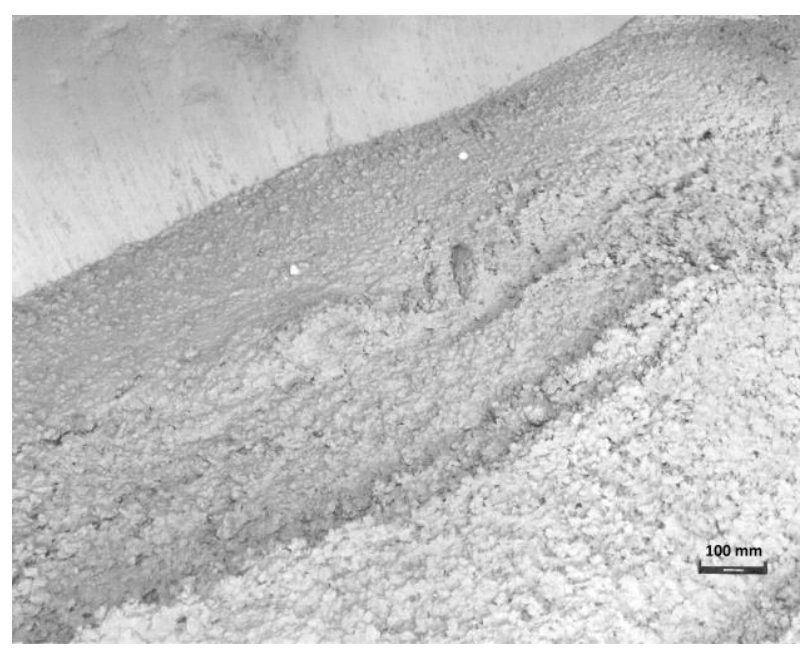

Rys. 1. Mieszanka betonowa B11 - piasek, kruszywo magnetytowe - konsystencja $120 \mathrm{~mm}$

Fig. 1. Concrete mixture B11 - sand, magnetite aggregate - consistency $120 \mathrm{~mm}$ 


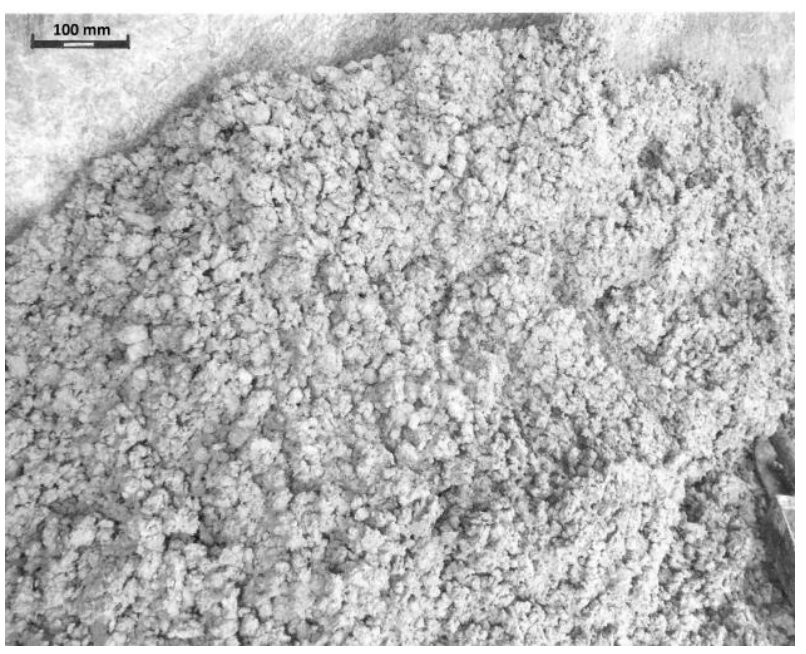

Rys. 2. Mieszanka betonowa B12 - piasek, kruszywo serpentynitowe - konsystencja $20 \mathrm{~mm}$

Fig. 2. Concrete mixture B12 - sand, serpentinite aggregate - consistency $20 \mathrm{~mm}$



Rys. 3. Mieszanka betonowa B18 - piasek, kruszywo serpentynitowe, kruszywo barytowe - konsystencja $100 \mathrm{~mm}$

Fig. 3. Concrete mixture B18 - sand, serpentinite aggregate, barite aggregate - consistency $100 \mathrm{~mm}$

Dla wykonanych mieszanek betonowych uzyskano duże różnice w konsystencji mierzonej za pomocą opadu stożka. Wynosiły one od 20 do $190 \mathrm{~mm}$. Różnica w konsystencji pomiędzy poszczególnymi mieszankami wynikała 
z przemysłowej technologii mieszania składników. W niektórych przypadkach przyjęte wcześniej ilości domieszek okazywały się niewystarczające do otrzymania projektowanej konsystencji jednak technologia mieszania składników w węźle betoniarskim wyklucza dodawanie domieszek do gotowej już mieszanki betonowej. Tym bardziej, że domieszka dodawana bez wody zarobowej nie działa w optymalny sposób. Należy jednak zaznaczyć, że wszystkie mieszanki wykazywały odpowiednią urabialność pozwalającą na układanie ich w deskowaniach.

\subsection{Metody badań}

Badania właściwości mieszanki betonowej przeprowadzono metodami normowymi: badanie konsystencji metodą opadu stożka wg PN-88/B-06250 lub PN-EN 12350-2, badanie gęstości objętościowej wg PN-EN 12350-6

Badanie wytrzymałości na ściskanie sześciennych próbek betonowych wykonano po upływie 28 dni, 56 dni oraz 90 dni od wykonania betonów. Do badań wykorzystano maszynę wytrzymałościową klasy I typu Dr MB-300, stosując normową metodę badania na ściskanie wg PN-EN 12390-3. W każdym terminie badane były trzy próbki. Próbki były wykonane, przechowywane i badane w akredytowanym Laboratorium badawczym „Hydrobudowy-1 Betoniarnia Laboratorium" Sp. z o.o.

Badanie skurczu betonu wykonano wg. Procedury HB-1 (IB-24) - wilgotność $65 \%, \mathrm{~T}=18 \pm 2{ }^{\circ} \mathrm{C}$ (Rys. 4 )

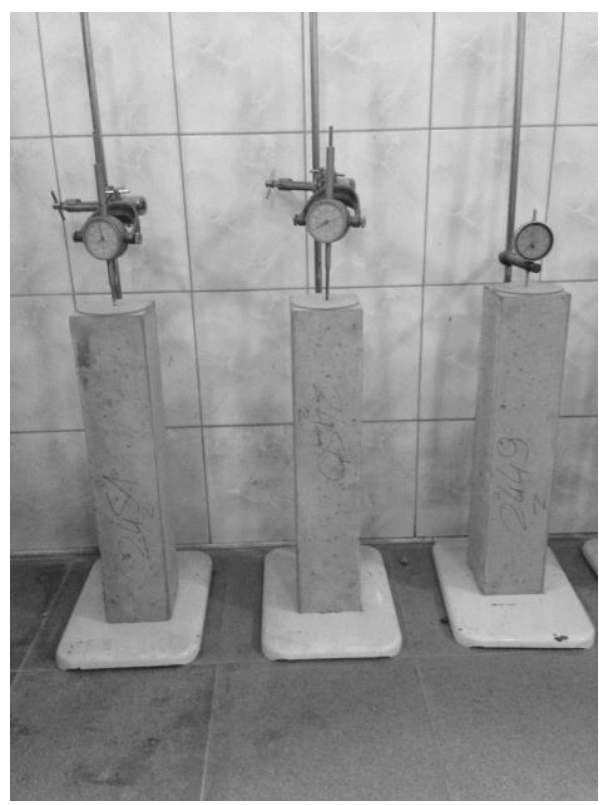

Rys. 4. Badanie skurczu betonu - stanowisko badawcze wg. Procedury IB-24

Fig. 4. Testing concrete shrinkage - test position by procedure IB-24 


\section{Wyniki badań}

Wyniki badań przedstawiono w Tabelach 3, 4 oraz na Rys. 5, 6. Podane wartości są wartościami średnimi z trzech badań.

Tabela 3. Średnie wyniki badań - Część 1

Table 3. Average testing results - Part 1 .

\begin{tabular}{|l|c|c|c|c|}
\hline & B11 & B12 & B13 & B14 \\
\hline $\begin{array}{l}\text { Wytrzymałość } \\
\text { na ściskanie }\end{array}$ & & & & \\
\hline po 28 dniach [MPa] & $53,7 \pm 4,7$ & $47,8 \pm 4,2$ & $52,9 \pm 4,6$ & $46,3 \pm 4,1$ \\
\hline po 56 dniach [MPa] & $57,6 \pm 5,0$ & $54,3 \pm 4,7$ & $58,6 \pm 5,1$ & $51,6 \pm 4,5$ \\
\hline po 90 dniach [MPa] & $62,7 \pm 5,5$ & $57,3 \pm 5,0$ & $59,3 \pm 5,2$ & $48,7 \pm 4,2$ \\
\hline & & & & \\
\hline Skurcz: & & & & \\
\hline po 7 dniach $[\mathrm{mm} / \mathrm{m}]$ & $0,15 \pm 0,01$ & $0,31 \pm 0,02$ & $0,23 \pm 0,01$ & $0,25 \pm 0,01$ \\
\hline po 14 dniach $[\mathrm{mm} / \mathrm{m}]$ & $0,29 \pm 0,01$ & $0,49 \pm 0,02$ & $0,36 \pm 0,02$ & $0,42 \pm 0,02$ \\
\hline po 21 dniach $[\mathrm{mm} / \mathrm{m}]$ & $0,35 \pm 0,02$ & $0,63 \pm 0,03$ & $0,40 \pm 0,02$ & $0,52 \pm 0,03$ \\
\hline po 28 dniach $[\mathrm{mm} / \mathrm{m}]$ & $0,38 \pm 0,02$ & $0,68 \pm 0,03$ & $0,46 \pm 0,02$ & $0,56 \pm 0,03$ \\
\hline po 56 dniach $[\mathrm{mm} / \mathrm{m}]$ & $0,46 \pm 0,02$ & $0,83 \pm 0,04$ & $0,57 \pm 0,03$ & $0,66 \pm 0,03$ \\
\hline po 90 dniach $[\mathrm{mm} / \mathrm{m}]$ & $0,49 \pm 0,02$ & $0,84 \pm 0,04$ & $0,62 \pm 003$ & $0,71 \pm 0,04$ \\
\hline
\end{tabular}

Tabela 4. Średnie wyniki badań - Część 2

Table 4. Average testing results - Part 2.

\begin{tabular}{|l|c|c|c|c|}
\hline & B15 & B16 & B17 & B18 \\
\hline $\begin{array}{l}\text { Wytrzymałość } \\
\text { na ściskanie: }\end{array}$ & & & & \\
\hline po 28 dniach [MPa] & $42,2 \pm 3,7$ & $42,6 \pm 3,7$ & $41,9 \pm 3,7$ & $48,7 \pm 4,2$ \\
\hline po 56 dniach [MPa] & $46,1 \pm 4,0$ & $44,7 \pm 3,9$ & $48,1 \pm 4,2$ & $56,4 \pm 4,9$ \\
\hline po 90 dniach [MPa] & $46,4 \pm 4,0$ & $48,6 \pm 4,2$ & $50,8 \pm 4,4$ & $58,7 \pm 5,1$ \\
\hline & & & & \\
\hline Skurcz: & & & & \\
\hline po 7 dniach $[\mathrm{mm} / \mathrm{m}]$ & $0,21 \pm 0,01$ & $0,13 \pm 0,01$ & $0,12 \pm 0,01$ & $0,11 \pm 0,01$ \\
\hline po 14 dniach $[\mathrm{mm} / \mathrm{m}]$ & $0,30 \pm 0,01$ & $0,21 \pm 0,01$ & $0,23 \pm 0,01$ & $0,25 \pm 0,01$ \\
\hline po 21 dniach $[\mathrm{mm} / \mathrm{m}]$ & $0,36 \pm 0,02$ & $0,26 \pm 0,01$ & $0,35 \pm 0,02$ & $0,38 \pm 0,02$ \\
\hline po 28 dniach $[\mathrm{mm} / \mathrm{m}]$ & $0,42 \pm 0,02$ & $0,30 \pm 0,01$ & $0,47 \pm 0,02$ & $0,52 \pm 0,03$ \\
\hline po 56 dniach $[\mathrm{mm} / \mathrm{m}]$ & $0,51 \pm 0,03$ & $0,39 \pm 0,02$ & $0,54 \pm 0,03$ & $0,59 \pm 0,03$ \\
\hline po 90 dniach $[\mathrm{mm} / \mathrm{m}]$ & $0,59 \pm 0,03$ & $0,43 \pm 0,02$ & $0,61 \pm 0,03$ & $0,67 \pm 0,03$ \\
\hline
\end{tabular}






Rys. 5. Wyniki badań wytrzymałości na ściskanie

Fig. 5. Average testing results of concrete's compressive strength



Rys. 6. Wyniki badań skurczu betonu - linia pozioma - przyjęta zwyczajowo dopuszczalna wartość skurczu $0,7 \mathrm{~mm} / \mathrm{m}$

Fig. 6. Average testing results of concrete shrinkage - horizontal line - established by custom permissible shrinkage value of $0.7 \mathrm{~mm} / \mathrm{m}$

Dla wszystkich wykonanych betonów po upływie 28 dni uzyskano projektowaną klasę C30/37. Wartości wytrzymałości na ściskanie betonu zależą od rodzaju zastosowanego kruszywa a w zasadzie od jego wytrzymałości. Najwyższe wytrzymałości otrzymano dla betonów z dużą ilością kruszywa magnetytowego a najniższe dla betonów z dużą ilością kruszywa barytowego. 
W sześciu betonach wartość skurczu po 90 dniach nie przekracza przyjętej zwyczajowo wartości dopuszczalnej, tj. $0,7 \mathrm{~mm} / \mathrm{m}$.

Wartości skurczu zależą od rodzaju zastosowanego kruszywa i są największe dla betonów z kruszywem serpentynitowym. Im więcej kruszywa serpentynitowego tym większy skurcz betonu. Betony z kruszywem magnetytowym i barytowym charakteryzują się podobnym skurczem. Zastąpienie około $20 \%$ objętości kruszywa barytowego piaskiem spowodowało zmniejszenie skurczu po 90 dniach o prawie $30 \%$.

\section{Wnioski}

Przeprowadzone badania pozwalają na sformułowanie następujących wniosków:

- Konsystencja mieszanki betonowej według opracowanych receptur umożliwia jej transport i wbudowanie w czasie odpowiadającym wymaganiom przemysłowej technologii betonu;

- Przy zastosowaniu kruszywa magnetytowego oraz piasku można uzyskać mieszankę betonową o gęstości około $3500 \mathrm{~kg} / \mathrm{m}^{3}$;

- Do mieszanek betonowych wykonanych z zastosowaniem kruszywa serpentynitowego należy stosować dużą ilość domieszki upłynniającej;

- Mieszanki z kruszywem serpentynitowym charakteryzują się niską konsystencją, nawet przy zastosowaniu dużej ilości domieszki upłynniającej. Należy brać to pod uwagę w przypadku wbudowywania mieszanki w szalunek a w szczególności przy transporcie i podawaniu mieszanki betonowej w deskowanie;

- W żadnej mieszance betonowej ani w próbkach betonowych nie zauważono rozsegregowania kruszyw;

- Z uwagi na trudności z uzyskaniem odpowiedniej konsystencji w mieszankach z dużą ilością kruszywa serpentynitowego oraz duży skurcz betonu przed kolejnym etapem badań odrzucono mieszanki B12, B14, B18.

Referat zostat przygotowany w ramach Projektu ,Trwatość $i$ skuteczność betonowych oston przed promieniowaniem jonizujacym w obiektach energetyki jadrowej”, PBSII/A2/15/2014.

\section{Literatura}

[1] Brandt Andrzej M., Jóźwiak-Niedźwiedzka Daria, Nowowiejski Grzegorz, Denis Piotr, Wyniki badania betonu osłonowego z kruszywem magnetytowym, Konferencja Dni Betonu, 13-15 Października 2014, Wisła, 839 - 850.

[2] Alexander M., Mindess S. (2005) Aggregates in concrete. Taylor \& Francis, 435. 
TESTING THE TECHNOLOGICAL PERFORMANCE CONCRETE SHIELDS IN CONCRETE PLANT

\section{S u m m a r y}

In the paper the technological tests of concretes for shields against ionizing radiation are presented. The concretes were composed with magnetite, serpentinite and barite aggregates. The aim of this part of investigations was to ensure necessary workability and strength and to limit shrinkage. In the paper 8 various mixture compositions are presented. Concretes were aged at standard conditions up to 90 days and compressive strength and shrinkage were determinated. In conclusion the compositions B12, B14, B18 are less appropriale for the next stage of the experiments.

Keywords: heavy concrete, magnetite aggregate, barite aggregate, serpentinite aggregate, compressive strength, shrinkage of concrete

Przestano do redakcji: 07.06.2016 $r$.

Przyjęto do druku: 30.06.2016 r.

DOI: $10.7862 / \mathrm{rb} .2016 .9$ 